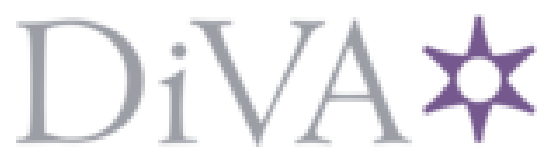

http://www.diva-portal.org

This is the published version of a paper presented at ASME Turbo Expo 2018:

Turbomachinery Technical Conference and Exposition, GT 2018, 11 June 2018 through 15 June 2018.

Citation for the original published paper:

Zaccaria, V., Stenfelt, M., Aslanidou, I., Kyprianidis, K. (2018)

Fleet monitoring and diagnostics framework based on digital twin of aero-engines

In: Proceedings of the ASME Turbo Expo American Society of Mechanical Engineers (ASME)

https://doi.org/10.1115/GT2018-76414

N.B. When citing this work, cite the original published paper.

Permanent link to this version:

http://urn.kb.se/resolve?urn=urn:nbn:se:mdh:diva-41129 


\section{FLEET MONITORING AND DIAGNOSTICS FRAMEWORK BASED ON DIGITAL TWIN OF AERO-ENGINES}

\author{
Valentina Zaccaria \\ Mälardalen University \\ Västerås, Sweden \\ loanna Aslanidou \\ Mälardalen University \\ Västerås, Sweden
}

\author{
Mikael Stenfelt \\ Mälardalen University \\ Västerås, Sweden \\ Konstantinos G. Kyprianidis \\ Mälardalen University \\ Västerås, Sweden
}

\begin{abstract}
Monitoring aircraft performance in a fleet is fundamental to ensure optimal operation and promptly detect anomalies that can increase fuel consumption or compromise flight safety. Accurate failure detection and life prediction methods also result in reduced maintenance costs. The major challenges in fleet monitoring are the great amount of collected data that need to be processed and the variability between engines of the fleet, which requires adaptive models.

In this paper, a framework for monitoring, diagnostics, and health management of a fleet of aircrafts is proposed. The framework consists of a multi-level approach: starting from thresholds exceedance monitoring, problematic engines are isolated, on which a fault detection system is then applied. Different methods for fault isolation, identification, and quantification are presented and compared, and the related challenges and opportunities are discussed. This conceptual strategy is tested on fleet data generated through a performance model of a turbofan engine, considering engine-to-engine and flight-to-flight variations and uncertainties in sensor measurements. Limitations of physics-based methods and machine learning techniques are investigated and the needs for fleet diagnostics are highlighted.
\end{abstract}

\section{NOMENCLATURE}
Abbreviations
BP Bypass
EHM Engine Health Monitoring
FC Flow Capacity
GPA Gas Path Analysis

$\begin{array}{ll}\text { HPC/HPT } & \text { High Pressure Compressor/Turbine } \\ \text { IPC/IPT } & \text { Intermediate Pressure Compressor/Turbine } \\ \text { LPC/LPT } & \text { Low Pressure Compressor/Turbine } \\ \text { NH } & \text { HP shaft speed } \\ \text { NI } & \text { IP shaft speed } \\ \text { ToC } & \text { Top of Climb } \\ \text { Wf } & \text { Fuel flow }\end{array}$

\section{Parameters}

$\begin{array}{ll}\mathrm{p} & \text { Pressure } \\ \mathrm{r} & \text { Residual } \\ \mathrm{s} & \text { Signature generated by a component fault } \\ \mathrm{T} & \text { Temperature } \\ \mathrm{Y} & \text { Generic parameter } \\ \mathrm{Z} & \text { Vector of normalized deltas } \\ \delta & \text { pressure correction factor } \\ \eta & \text { Isentropic Efficiency } \\ \theta & \text { temperature correction factor } \\ \Phi & \text { Correlation }\end{array}$

Subscripts
$\begin{array}{ll}\text { amb } & \text { ambient } \\ \text { corr } & \text { corrected } \\ \text { ref } & \text { reference }\end{array}$

\section{INTRODUCTION}

Engines are responsible for roughly $25 \%$ of the total direct operating costs of aircraft [1]. Therefore, airline operators demand reduced maintenance costs and longer availability. Fault 
detection and identification becomes extremely important, as a first step toward component life prediction and condition based maintenance. Engine usage and maintenance can be planned more effectively if data on individual component condition are available while operating on-wing. The necessary corrective actions can then be established to avoid unsafe operations or excessive fuel consumption. At the same time, unnecessary maintenance time can be avoided if the engine is still in healthy condition. For the airlines to remain in operation, it is critical to maintain high efficiency, availability, and reliability of the engines in the fleet. A robust monitoring, diagnostics, and prognostics framework has been demonstrated a valuable tool to reduce ownership and maintenance costs [2].

The most utilized diagnostic method is based on gas path analysis (GPA) [3-7]. Existing approaches can be grouped in three categories: physics-based methods, data-driven methods, and hybrid methods. A recent review of the most utilized approaches and applications for condition based maintenance was presented by Tehan et al. [8]. Nowadays, the digitalization of operations and condition monitoring, data acquisition, and maintenance planning has enabled a totally different way of managing airline fleets [9, 10]. The manufacturers are using digital twins to simulate fleets of engines and monitor their operation. Huge amounts of data are collected into digital platforms for optimization of flight operations and maintenance, resulting in consistent savings for the airlines.

In the currently deployed systems, an automated anomaly detection approach is generally applied based on threshold exceedance [11]. The reported anomalies are then fed to a diagnostic tool for isolation and identification of the fault. Large airline companies often use performance models provided by engine manufacturers and monitor mismatches between the physics-based models and the flight data. Since these models are proprietary, an alternative is given by data-driven models [1215]. The main drawback of this approach lies in the massive amounts of historical data needed for training (and re-training) and their limited availability. Adaptive performance models are particularly attractive for diagnostic purposes, since they can be used for accurate GPA and also provide training data for machine learning systems [16-18].

The factors that influence the diagnostic system in an aircraft and particularly in a fleet are numerous, rendering the task of engine monitoring and diagnostics more challenging:

- Limited number of sensors due to space, weight, and cost constraints

- Measurement uncertainty

- Serial deviation between engines in the fleet (production scatter)

- Differences between new and degraded engines

- Large amount of data that need to be collected, processed, and used.

Because of the large amount of data, an automated method is necessary. Automated algorithms for fault detection and isolation have been proposed exploiting many different techniques, but they are usually tested on a single engine or engine model [19-22]. It was pointed out at first by Zur Nieden et al. that engine performance deviations in a fleet are not negligible and can negatively affect anomaly detection [23]. To mitigate this issue, several authors developed adaptive or regression models and data driven approaches for diagnostic purposes [11, 24-26].

Scalable, regression models for a fleet of aircraft engines were developed [24, 25] for anomaly detection to solve two major issues: performance variability within the fleet due to production scattering and potential computational burden due to the large amount of collected data. The proposed methods can fit the optimization problem into the memory of a normal computer. Chu et al. tested their algorithm on three scenarios: a performance anomaly detection, a performance shift detection over different flights, and an anomalous aircraft, implanting 6 cases over 200 aircrafts. A scalable approach for anomaly detection of a large population of aircraft was also proposed by Ohlsson et al., with the important advantage of no training needed for the algorithm [27].

Scheianu presented a framework for land-based gas turbine fleet monitoring and diagnostics [28]. The requirements of the framework are identified as an automated data processing, management, and visualization system, automated alerts, and forecast of engine operations to predict service and maintenance needs. The framework included a regression method for modeling each machine in the fleet. Gradual degradation and abrupt faults were successfully detected by monitoring of performance indices. Martinez et al. proposed a fuzzy logic based technique for engine health monitoring (EHM) that classified the engines of the fleet as good, normal, highly deteriorated, and bad [29]. Their approach was a significant step towards a method to minimize maintenance cost in a fleet. A GPA approach was presented and tested on flight data from a KLM aircraft assessing the effect of sensor noise, but complete fleet monitoring and diagnostics were not presented [30].

The applications of diagnostics and prognostics tools to a fleet of engines are limited in the open literature. The challenge of adapting a model to different engines in the fleet for modelbased diagnostics has been addressed, as discussed previously [11, 17, 24-26]. However, examples of an EHM framework tested on fleet data have not been extensively presented. One reason is the limitation in accessing flight data of an entire fleet. In this paper, a framework for fleet monitoring and diagnostics is described and its performance assessed by use of generated fleet data with an adaptive, physics-based digital twin of a threeshaft turbofan.

The novelty of this work lies in addressing the following points:

- $\quad$ Present and test a monitoring and diagnostic framework for a fleet of engines, from anomaly detection to fault quantification;

- Generate fleet data by means of an adaptive physicsbased engine model using Monte Carlo simulations; 
- Discuss the use of physics-based models and datadriven approaches for fleet diagnostics.

\section{FRAMEWORK DESCRIPTION}

A proposed framework for monitoring, diagnostics, and health management of a fleet of engines is presented in this section. The framework is based on an adaptive physics-based performance model of the engine, which is used as a digital twin to generate fault signatures that can be compared with measured flight data to assess the engine conditions. A schematic of the framework is depicted in Figure 1.

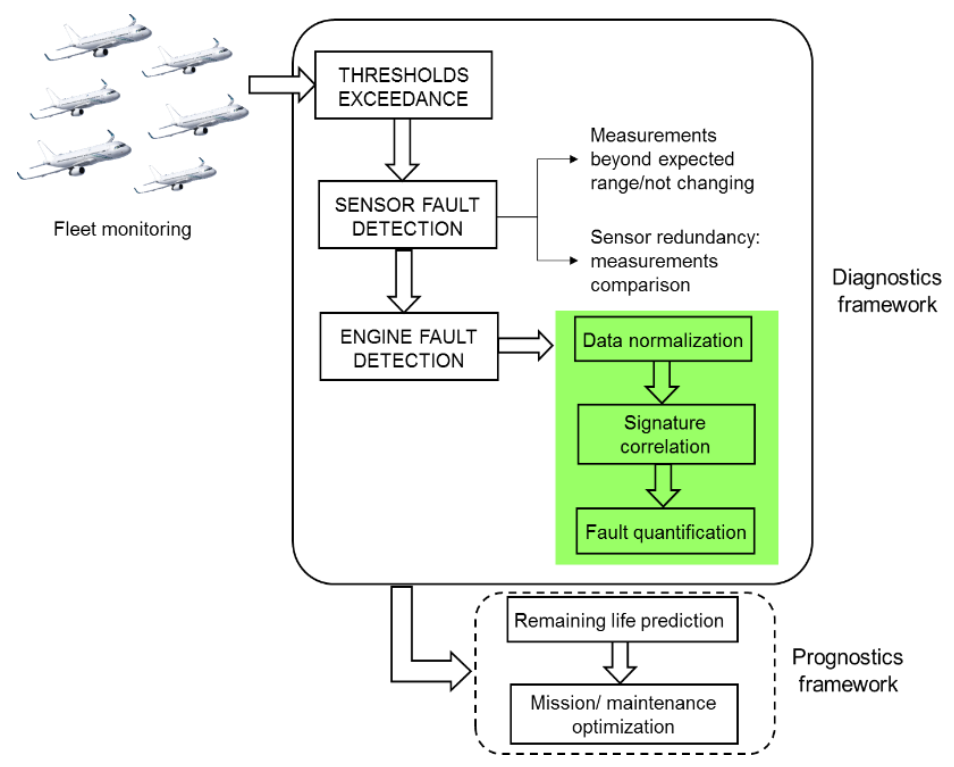

Fig. 1. Proposed diagnostics framework

The proposed diagnostics framework consists of the following multi-level approach:

- Data pre-processing

- Threshold monitoring and anomaly detection

- Sensor fault detection

- Engine fault detection and isolation

- Fault identification

\section{Data correction}

Fleet data are filtered and corrected with reference conditions, and subsequently, normalized deltas from the baseline engine in healthy conditions are calculated. Correction and normalization processes are illustrated in Equations 1 and 2, as suggested in [6].

$$
\begin{aligned}
& Y_{\text {corr }}=\frac{Y}{\theta^{a} \delta^{b}} \\
& \Delta Y=\frac{Y_{\text {nominal }}-Y_{\text {corr }}}{Y_{\text {nominal }}}
\end{aligned}
$$

Where $Y$ is a generic parameter, and $\theta$ and $\delta$ are expressed as in Equations 3 and 4, with $T_{r e f}=288.15 \mathrm{~K}$ and $p_{r e f}=101.325 \mathrm{kPa}$. The exponents $a$ and $b$ depend on the engine type and cycle, and on the parameter to be corrected, e.g. $\mathrm{a}=1$ and $\mathrm{b}=0$ when $Y$ is a temperature measurement, while $a=-1 / 2$ and $b=1$ to correct a mass flow measurement [6].

$$
\begin{aligned}
& \theta=\frac{T}{T_{\text {ref }}} \\
& \delta=\frac{p}{p_{\text {ref }}}
\end{aligned}
$$

Corrected data are compared with expected values, and if the difference exceeds a predefined threshold, an anomaly is detected and the engine is isolated for further investigation.

A first level of sensor fault assessment is performed checking whether measurements are out of range (for example if a pressure measurement is negative) or not changing over time. A more accurate sensor fault assessment could be done with redundant sensors, comparing two measurements of the same variable; the additional cost and weight introduced by extra sensors needs to be carefully investigated, but could be compensated by a more accurate EHM tool and consequent reduction of operational and maintenance costs. The following results will focus on the engine fault detection and identification steps.

\section{Fault isolation algorithm}

The second fault assessment is carried out on the engine by means of a signature-based algorithm. The digital twin of the average engine is used to reproduce fault signatures of 12 main component faults, i.e. a $1 \%$ drop in isentropic efficiency or flow capacity in one of the following components (for a three-shaft turbofan):

- Fan

- Intermediate pressure compressor (IPC)

- High pressure compressor (HPC)

- High pressure turbine (HPT)

- Intermediate pressure turbine (IPT)

- Low pressure turbine (LPT)

More sophisticated sensor fault detection could be included in this algorithm, but it is not considered in this work. A correlation function is then applied to each signature with respect to the measured values, according to Equation 5, and the component fault is isolated as the one that gives the highest correlation. The index $i$ refers to the measurement variable ( 8 in total, as presented in the next section), $z$ is the vector of normalized deltas $\Delta Y, s_{n}$ the signature generated by a fault in the $\mathrm{n}$-th component, and $\Phi_{\mathrm{n}}$ is the correlation parameter. The vector $z$ has 8 components, corresponding to the 8 sensors present on the engine. The signature vector is equal to $z$ when a fault of $1 \%$ is implemented in one of the 12 components. 


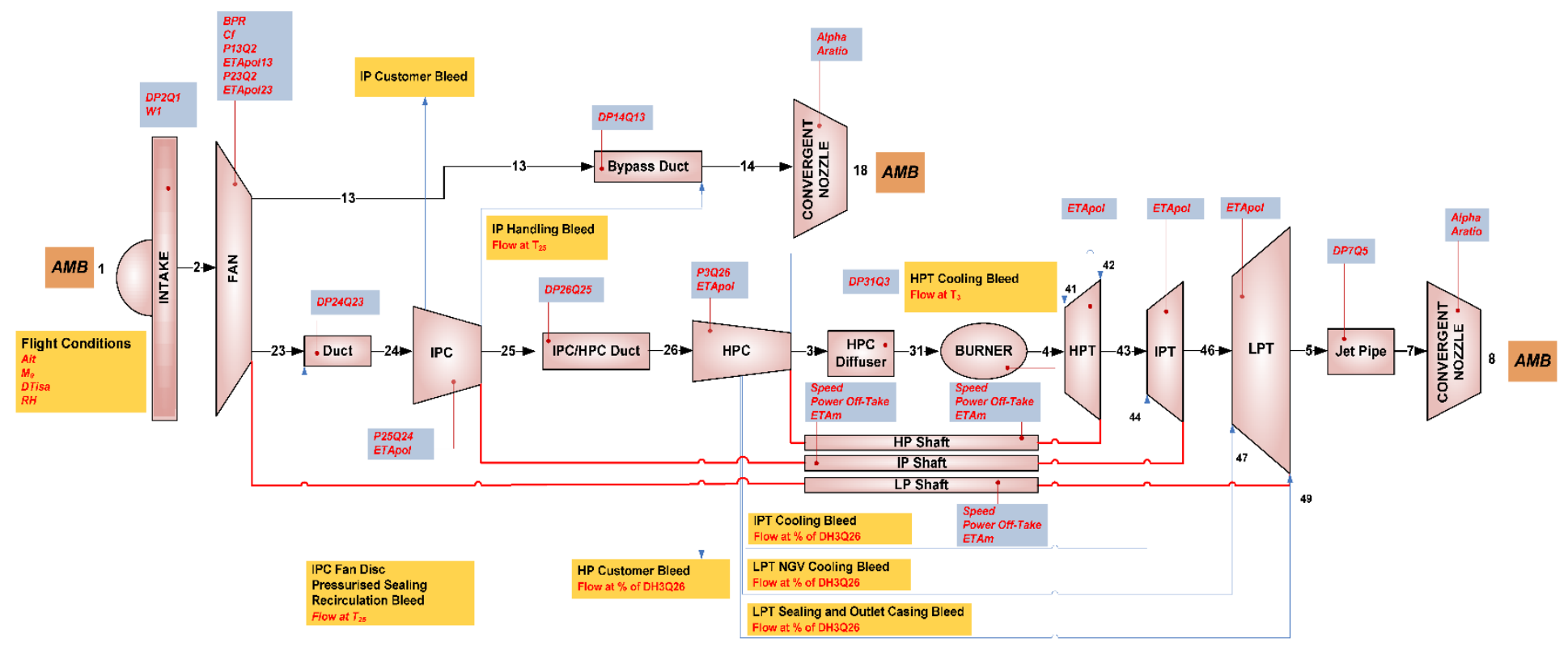

Fig. 2. Schematic diagram of the three-shaft turbofan model

$$
\Phi_{n}=\frac{\sum_{i=1}^{8}\left(s_{n, i}-\bar{s}_{n}\right)\left(z_{i}-\bar{z}\right)}{\sqrt{\sum_{i=1}^{8}\left(s_{n, i}-\bar{s}_{n}\right)^{2} \sum_{i=1}^{8}\left(z_{i}-\bar{z}\right)^{2}}}
$$

Fault identification (i.e. magnitude quantification) is performed by minimizing the residuals shown in Equation 6 . Results from the diagnostics framework can be used to assess and predict engine lifetime, optimize flight operations, and improve maintenance strategy [31].

$r=\sqrt{\sum\left|z_{i}-s_{i}\right|^{2}}$

A neural network $(\mathrm{NN})$ classifier was also developed for fault identification to compare a data-driven method with the signature based approach. A back-propagation NN with 10 neurons-single layer was employed. A combination of physicsbased and data-driven algorithms, as well as the use of physicsbased performance models for $\mathrm{NN}$ training, have been demonstrated effective in previous work for fault diagnostics $[18,32]$.

\section{FLEET DATA GENERATION}

\section{Model description}

A physics-based model of a three-shaft, high bypass turbofan implemented in an in-house performance simulation code was used to demonstrate the fleet monitoring and diagnostics framework in this paper.

A description of the simulation tool and the model components can be found in previous publications [33]. The tool comprises various modules, among which, the engine performance module was employed in this work. The modelling was based on fundamental thermodynamic equations, generic compressor and turbine characteristics, as well as empirical correlations [34]. Thermodynamic calculations were based on the assumption of an ideal gas and solved through Gibbs equations. Components efficiency are modelled as discussed in [35]. A schematic diagram of the engine under investigation is presented in Figure 2.

The nominal conditions at top of climb (ToC) are reported in Table 1. The model is representative of a 70,000 lbf engine with technology levels consistent with entry into service in 1995. The diagnostic framework was tested with the engine at steadystate in ToC conditions.

Table 1. Nominal conditions at ToC

\begin{tabular}{|c|c|}
\hline Flight altitude & $10668 \mathrm{~m}$ \\
\hline Flight Mach no. & 0.82 \\
\hline Bypass ratio & 4.7 \\
\hline Overall pressure ratio & 34 \\
\hline HPT inlet temperature & $1625 \mathrm{~K}$ \\
\hline Specific thrust & $167 \mathrm{~N} \cdot \mathrm{s} / \mathrm{kg}$ \\
\hline
\end{tabular}

\section{Production scattering simulation}

In order to simulate a fleet of similar engines, information on the production scattering was included in the model. Different units of the same engine were modelled by including a probabilistic distribution of isentropic efficiency and flow capacity of the various rotating components. A triangular distribution was assumed for the deltas in efficiency and flow capacity between the specific engine and the baseline nominal values. The most likely value was set to zero (no deviation from baseline engine) for the efficiencies and 1 for the flow capacities, and expected deviations were assumed as shown in Table 2. 


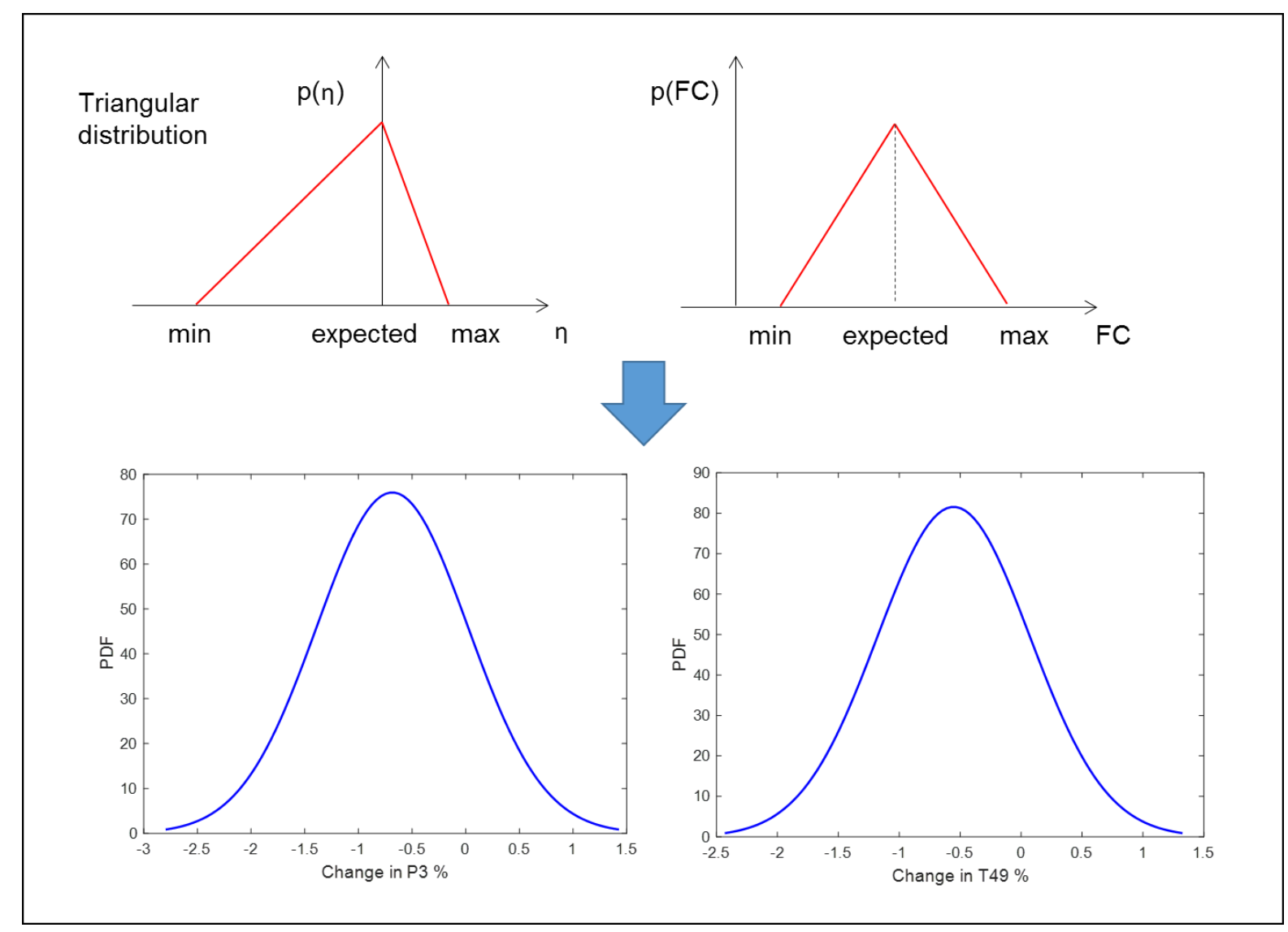

Fig. 3. Example of production scatter implementation and resulting measurements deviation

In the same way, a similar delta distribution can be used to represent engines that degraded from their design condition.

Table 2. Probabilistic distributions for production scatter

\begin{tabular}{|c|c|c|}
\hline Parameter & Max variation & Min variation \\
\hline$\eta_{\text {fan }}$ & $0.1 \%$ & $-0.3 \%$ \\
\hline $\mathrm{FC}_{\text {fan }}$ & 1.01 & 0.99 \\
\hline$\eta_{\mathrm{IPC}}$ & $0.5 \%$ & $-1 \%$ \\
\hline $\mathrm{FC}_{\mathrm{IPC}}$ & 1.01 & 0.99 \\
\hline$\eta_{\mathrm{HPC}}$ & $0.6 \%$ & $-0.6 \%$ \\
\hline $\mathrm{FC}_{\mathrm{HPC}}$ & 1.01 & 0.99 \\
\hline$\eta_{\mathrm{HPT}}$ & $0.5 \%$ & $-0.5 \%$ \\
\hline $\mathrm{F} \mathrm{C}_{\mathrm{HPT}}$ & 1.01 & 0.99 \\
\hline$\eta_{\mathrm{IPT}}$ & $0.15 \%$ & $-0.35 \%$ \\
\hline $\mathrm{F} C_{\mathrm{IPT}}$ & 1.015 & 0.985 \\
\hline$\eta_{\mathrm{LPT}}$ & $0.5 \%$ & $-0.5 \%$ \\
\hline $\mathrm{FC}_{\mathrm{LPT}}$ & 1.005 & 0.995 \\
\hline
\end{tabular}

Table 2 shows the maximum and minimum values for the production deltas used in this work, representing the maximum expected difference between two units of the same engine. These values were chosen consistently with serial deviations for common engines.

Table 3. Standard deviations for the considered sensors

\begin{tabular}{|c|c|}
\hline NI (IP shaft speed) & $0.05 \%$ \\
\hline NH (HP shaft speed) & $0.05 \%$ \\
\hline WF (fuel flow) & $0.5 \%$ \\
\hline T25 & $0.4 \%$ \\
\hline T3 & $0.4 \%$ \\
\hline T49 & $0.4 \%$ \\
\hline P25 & $0.25 \%$ \\
\hline P3 & $0.25 \%$ \\
\hline T1 & $0.4 \%$ \\
\hline P1 & $0.25 \%$ \\
\hline
\end{tabular}

A Monte Carlo simulation was used to generate the fleet data with random production scatter according to the values in Table 2. Measurement noise was also included, according to the values in Table 3. 1000 points were generated, with efficiencies and flow capacities variations corresponding to the random difference between the different engines and between flights of the same engine (same flight conditions but with sensors deviations). This procedure is summarized in Figure 3: triangular distributions were implemented for components efficiency and 
flow capacity, resulting in deviations of measured parameters from the design value.

For the practical implementation of the diagnostic framework on a fleet of engines, the production scatter effect needs to be estimated from the performance test of each engine. Regression methods have been applied in the literature for the purpose of adapting a model to experimental performance data $[11,26]$. In this way, the differences between each specific engine in healthy condition and the baseline model can be determined from test data and the model parameters can be adjusted for each engine. This work assessed the advantage of using a hybrid physics-based and data-driven model for fault detection and isolation. The simple signature-based system was then compared to a purely data-driven approach using a neural network trained on the fleet data generated by the engine model.

\section{RESULTS AND DISCUSSION}

For each of the 1000 data points of the fleet, a drop of $1 \%$, $2 \%$, and $3 \%$ in efficiency or flow capacity in one component was simulated, and this was done for all six main components of the engine. Therefore, a total of 36 fault cases were simulated, as summarized in Table 4. For this work, only single faults were tested (e.g. only one efficiency degradation or one flow capacity degradation at a time). However, the signature based algorithm can be applied similarly to multiple faults. Flight conditions were maintained the same for the test (i.e. at ToC).

Table 4. Summary of the fault cases

\begin{tabular}{|l|l|l|l|}
\hline Component & \multicolumn{2}{|l|}{ Parameter } & \multicolumn{2}{l|}{$\begin{array}{l}\text { Fault } \\
\text { magnitude }\end{array}$} \\
\hline Fan & $\eta$ & FC & $1 \%, 2 \%, 3 \%$ \\
\hline IPC & $\eta$ & FC & $1 \%, 2 \%, 3 \%$ \\
\hline HPC & $\eta$ & FC & $1 \%, 2 \%, 3 \%$ \\
\hline HPT & $\eta$ & FC & $1 \%, 2 \%, 3 \%$ \\
\hline IPT & $\eta$ & FC & $1 \%, 2 \%, 3 \%$ \\
\hline LPT & $\eta$ & FC & $1 \%, 2 \%, 3 \%$ \\
\hline
\end{tabular}

Figure 4 depicts healthy and faulty engines on the compressor map, where the orange dots denote engines with an implanted fault. The significant performance scatter represents an important challenge for anomaly detection, because less severe faults are not always distinguished from healthy engines.

\section{Anomaly detection}

As first step, the corrected data were compared with expected values; when the difference exceeds a predefined threshold, an anomaly is detected. Corrected data were normalized with the baseline values in nominal conditions according to Eq. 2. The threshold was set as $\pm 3 \sigma$ (standard deviations) of each parameter distribution. An example is shown in Figures 5 and 6, where the collected values of T49 and P3 for 500 healthy and faulty engines are compared.

For multiple faulty engines, the measurements deviation lies within the production scatter, as seen from Fig. 5 and 6.
However, when combining measurements from the 8 available sensors, the faulty engines can be detected and isolated.

Several healthy engines were also considered faulty by looking at the deviation from the expected values, as it is possible to notice in Fig. 5 and 6 where a few blue dots exceed the threshold. In this case, however, the fault identification system assessed that no fault was present in any of the components, as discussed in the next section.

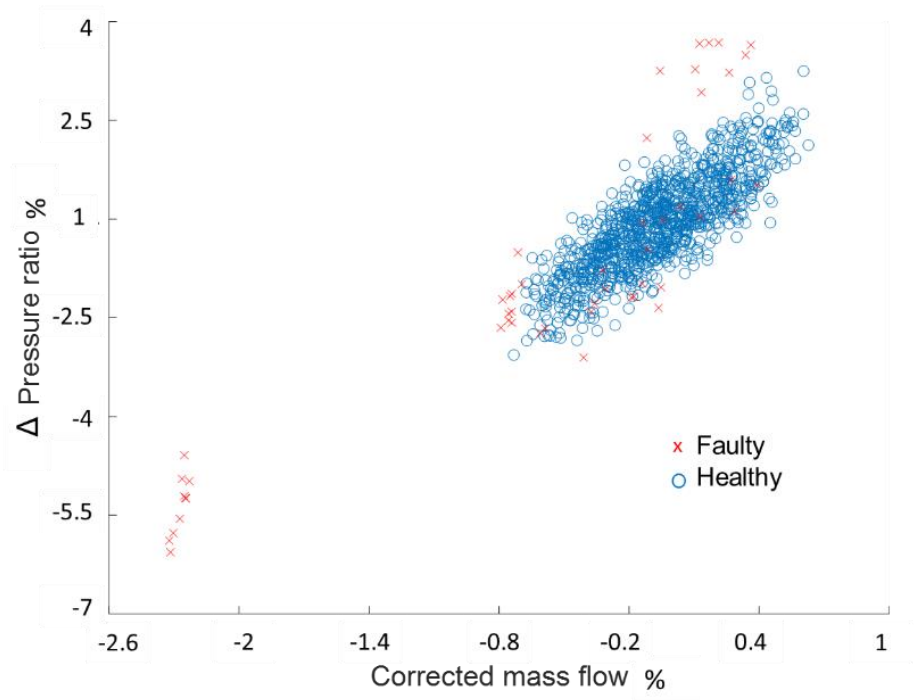

Fig. 4. Healthy and faulty engine representation on the compressor map

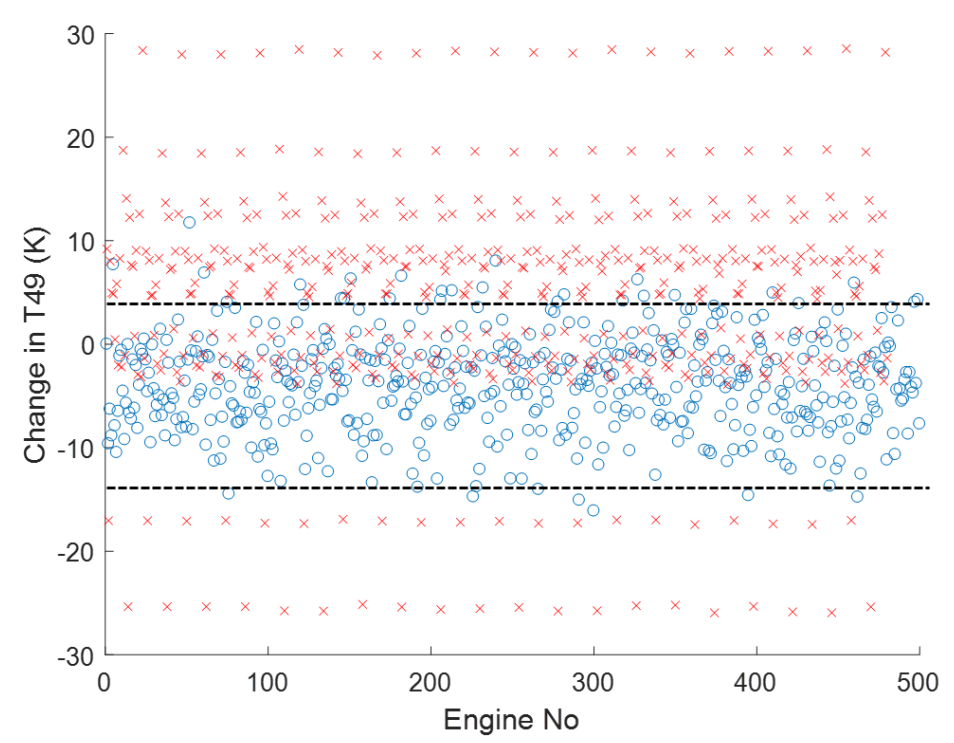

Fig. 5. Variation in T49 for various healthy (o) and faulty (x) engines 


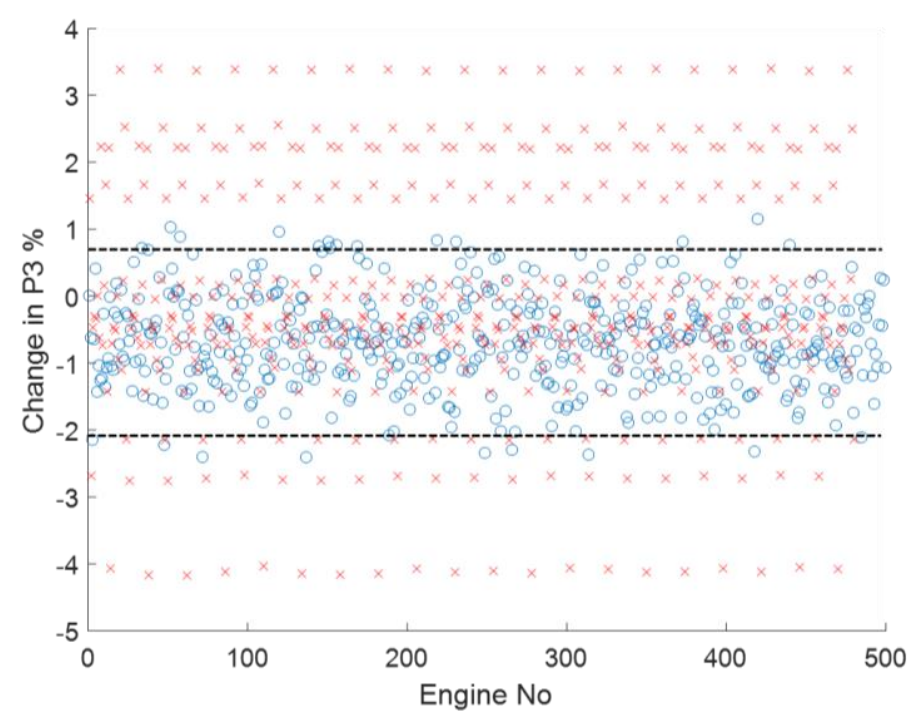

Fig. 6. Normalized P3 variations for various healthy (o) and faulty (x) engines

\section{Fault detection and identification}

The fault detection algorithm described in the Framework Description section was applied to the 36 cases shown in Table 4. Two different approaches for data normalization were compared: i) the fleet data including production scatter and flight-to-flight differences are normalized against the baseline engine design value (i.e. same value for each data point), or ii) each data point was normalized against the specific engine nominal (i.e. healthy) conditions, which included the variation due to production scatter. Both nominal values (baseline and specific engine) were generated through the performance model.

Table 5. Faults classified correctly in case of normalization with baseline engine

\begin{tabular}{|l|l|l|l|}
\hline $\begin{array}{l}\text { Fault type/ fault } \\
\text { implanted }\end{array}$ & $\mathbf{1 \%}$ & $\mathbf{2 \%}$ & $\mathbf{3 \%}$ \\
\hline$\eta_{\mathrm{fan}}$ & $9.60 \%$ & $8.90 \%$ & $10.30 \%$ \\
\hline $\mathrm{FC}_{\mathrm{fan}}$ & $1.60 \%$ & $1.90 \%$ & $1.70 \%$ \\
\hline$\eta_{\mathrm{IPC}}$ & $0.40 \%$ & $0.00 \%$ & $0.00 \%$ \\
\hline $\mathrm{FC}_{\mathrm{IPC}}$ & $0.50 \%$ & $0.40 \%$ & $0.50 \%$ \\
\hline$\eta_{\mathrm{HPC}}$ & $2.00 \%$ & $1.90 \%$ & $3.40 \%$ \\
\hline $\mathrm{FC}_{\mathrm{HPC}}$ & $0.40 \%$ & $0.60 \%$ & $0.90 \%$ \\
\hline$\eta_{\mathrm{HPT}}$ & $7.60 \%$ & $7.50 \%$ & $6.00 \%$ \\
\hline $\mathrm{FC}_{\mathrm{HPT}}$ & $1.30 \%$ & $1.00 \%$ & $1.60 \%$ \\
\hline$\eta_{\mathrm{IPT}}$ & $16.20 \%$ & $14.70 \%$ & $16.90 \%$ \\
\hline $\mathrm{FC}_{\mathrm{IPT}}$ & $2.40 \%$ & $2.60 \%$ & $2.50 \%$ \\
\hline$\eta_{\mathrm{LPT}}$ & $7.50 \%$ & $4.50 \%$ & $7.40 \%$ \\
\hline $\mathrm{FC}_{\mathrm{LPT}}$ & $9.80 \%$ & $9.90 \%$ & $10.00 \%$ \\
\hline Total & $\mathbf{4 . 9 \%}$ & $\mathbf{4 . 5 \%}$ & $\mathbf{5 . 1 \%}$ \\
\hline
\end{tabular}

The fault signatures of Equation 5 were calculated with the baseline engine model by implanting a single $1 \%$ fault in each of the components. Thus, a signature database was created with 12 signatures.

Results from the first case (normalization with baseline engine values) are presented in Table 5. The fault isolation algorithm performed very poorly in this case, because the deltas introduced by production scatter are comparable with the ones caused by the actual fault, as seen in the measurements distributions in Fig. 5 and 6. Therefore, the diagnostic algorithm recognizes a fault even when the component is healthy and the difference from the baseline engine is merely due to engine-toengine design variations or engine deterioration between flights. Only $5 \%$ of the implanted faults were classified correctly; in the remaining cases, a fault was identified in a wrong component.

When normalizing the data with the engine-specific nominal conditions, the results were very different: $98.2 \%$ of implanted faults were correctly classified. In particular, $100 \%$ of the 12 single faults were correctly identified regardless of the severity, and the only misclassifications occurred when the analyzed engine was actually healthy and a fault was however detected. These false positives corresponded to $1.8 \%$ of the analyzed engines and were however correctly classified during the identification step, as explained below.

A fairly accurate identification of fault severity was possible using Equation 6: in 78\% of test cases, the error in the estimated fault severity was below $5 \%$; in $14 \%$ of the cases, the error was between 5 and $10 \%$; and the remaining $8 \%$ of test cases reported an error between 10 and $20 \%$ in estimated fault severity. In this phase, misclassifications were corrected because the healthy engines returned a fault severity of zero. An example of a random engine tested is shown in Table 6 , where the faults estimated by the algorithm are presented for each fault case of 1,2, and 3\% and for the healthy engine.

Table 6. Example of estimated fault severity (\%) for a random engine for each fault case

\begin{tabular}{|l|l|l|l|l|}
\hline $\begin{array}{l}\text { Fault type/ fault } \\
\text { implanted }\end{array}$ & $\mathbf{0 \%}$ & $\mathbf{1 \%}$ & $\mathbf{2 \%}$ & $\mathbf{3 \%}$ \\
\hline$\eta_{\text {fan }}$ & 0 & 0.908 & 1.868 & 2.888 \\
\hline $\mathrm{FC}_{\text {fan }}$ & 0 & 1.013 & 2.082 & 3.150 \\
\hline$\eta_{\mathrm{IPC}}$ & 0 & 1.014 & 2.052 & 3.113 \\
\hline $\mathrm{FC}_{\mathrm{IPC}}$ & 0 & 0.963 & 1.963 & 2.990 \\
\hline$\eta_{\mathrm{HPC}}$ & 0 & 1.068 & 2.195 & 3.387 \\
\hline $\mathrm{FC}_{\mathrm{HPC}}$ & 0 & 0.886 & 2.060 & 3.565 \\
\hline$\eta_{\mathrm{HPT}}$ & 0 & 0.988 & 1.997 & 3.019 \\
\hline $\mathrm{FC}_{\mathrm{HPT}}$ & 0 & 1.009 & 2.037 & 3.086 \\
\hline$\eta_{\mathrm{IPT}}$ & 0 & 0.999 & 1.996 & 2.993 \\
\hline $\mathrm{FC}_{\mathrm{IPT}}$ & 0 & 0.994 & 2.024 & 3.089 \\
\hline$\eta_{\mathrm{LPT}}$ & 0 & 0.984 & 1.996 & 3.036 \\
\hline $\mathrm{FC}_{\mathrm{LPT}}$ & 0 & 0.982 & 1.951 & 2.909 \\
\hline
\end{tabular}

The results highlight the necessity of an adaptive model for fleet diagnostic applications, with the capability to: i) adapt nominal values of component efficiency and flow capacity for 
each engine based on engine serial deviations, and ii) adapt the same values based on gradual deterioration of the engine, when coupled with a degradation tracking system. Accurate fault classification and identification is possible with fairly simple methods even when facing strong variations from engine to engine and from flight to flight.

A further enhancement of the framework can be provided by the combination with an on-board data-driven method such as a neural network classifier. As is the case with other data-driven methods, NN models have the disadvantage of requiring a substantial amount of training, and a sufficient amount of flight data is often not available for training.

The adaptive, physics-based model of the aero-engine was used to generate flight data to train a back-propagation $\mathrm{NN}$ with single layer. The NN was used with both approaches for data normalization to compare the results with those from the physics-based model. The classified faults in case of normalization of data with the baseline engine are shown in Table 7 . Around $60 \%$ of the faults were correctly classified in this case, regardless of the severity, which showed that the NN classifier performed better than the signature-based algorithm.

Table 7. NN correct fault classification in case of normalization with baseline engine

\begin{tabular}{|c|c|}
\hline$\eta_{\text {fan }}$ & $73.3 \%$ \\
\hline $\mathrm{FC}_{\text {fan }}$ & $66.1 \%$ \\
\hline$\eta_{\mathrm{IPC}}$ & $94.3 \%$ \\
\hline $\mathrm{FC}_{\mathrm{IPC}}$ & $60.8 \%$ \\
\hline$\eta_{\mathrm{HPC}}$ & $86.4 \%$ \\
\hline $\mathrm{FC}_{\mathrm{HPC}}$ & $45.6 \%$ \\
\hline$\eta_{\mathrm{HPT}}$ & $47.6 \%$ \\
\hline $\mathrm{FC}$ & $57 \%$ \\
\hline$\eta_{\mathrm{HPT}}$ & $53.3 \%$ \\
\hline $\mathrm{FC}$ & $48.5 \%$ \\
\hline$\eta_{\mathrm{IPT}}$ & $59.7 \%$ \\
\hline $\mathrm{FC}$ & $48.4 \%$ \\
\hline Total & $\mathbf{5 7 . 4 \%}$ \\
\hline
\end{tabular}

When testing the same NN model on the flight data normalized with the specific engines, the faults were correctly classified in $100 \%$ of the tested cases, as summarized in Table 8 .

Table 8. NN correct fault classification in case of normalization with specific engine

\begin{tabular}{|c|c|}
\hline$\eta_{\text {fan }}$ & $100 \%$ \\
\hline $\mathrm{FC}_{\mathrm{fan}}$ & $100 \%$ \\
\hline$\eta_{\mathrm{IPC}}$ & $100 \%$ \\
\hline $\mathrm{FC}_{\mathrm{IPC}}$ & $100 \%$ \\
\hline$\eta_{\mathrm{HPC}}$ & $100 \%$ \\
\hline $\mathrm{FC}_{\mathrm{HPC}}$ & $100 \%$ \\
\hline$\eta_{\mathrm{HPT}}$ & $100 \%$ \\
\hline $\mathrm{FC}_{\mathrm{HPT}}$ & $100 \%$ \\
\hline$\eta_{\mathrm{IPT}}$ & $100 \%$ \\
\hline $\mathrm{FC}_{\mathrm{IPT}}$ & $100 \%$ \\
\hline$\eta_{\mathrm{LPT}}$ & $100 \%$ \\
\hline
\end{tabular}

\begin{tabular}{|c|c|}
\hline FC $_{\text {LPT }}$ & $100 \%$ \\
\hline Total & $\mathbf{1 0 0 \%}$ \\
\hline
\end{tabular}

The need for a substantial amount of flight data to train the NN normally represents a considerable drawback of this technique, but it can be overcome by generating the necessary data with the adaptive performance model. The benefit of a NN (or a different machine learning algorithm) over the signaturebased one can be for on-wing diagnostics, where computational limitations of on-board systems can prevent the use of a complex physics-based model. The combination of an on-board NN diagnostics system and an off-line hybrid physics-based and data-driven approach can constitute a framework for accurate engine diagnostics in a fleet.

\section{Prognostics capability - Future extension}

A further step in the framework development will be the extension to prognostics and remaining life prediction. Estimated fault severity and monitored gradual deterioration can provide inputs for a decision support system on flight operations and maintenance. Engine deterioration level can be used to optimize maintenance intervals, but also to strategically plan flight missions, such as flight duration and route. The hybrid approach of physics-based and data-driven models can be employed for remaining lifetime estimation.

\section{CONCLUSIONS AND FUTURE WORK}

A framework for monitoring and diagnostics of a fleet of aircraft engines was presented in this paper. A multi-level approach was proposed, from anomaly detection to fault quantification. The challenge of considerable variations within engines in the fleet and within flights of the same engine was addressed by using an adaptive physics-based model as a digital twin for fault detection, isolation, and identification. Fault signatures were generated with the engine model and matched with fleet data. The approach was compared to a neural network fault classifier, showing that the simple signature-based technique can correctly identify $100 \%$ of the single faults when the adaptive model is used to simulate the engine production scatter and measurement uncertainty. However, it is essential to normalize the fleet data against the specific engine design conditions, because the deviations between units of the same engine are significant compared to the deviations caused by faults.

The physics-based performance model was also used to generate fleet data by means of Monte Carlo simulations, including engine serial deviations and flight-to-flight variations. This approach proved to be valuable for a double purpose: testing the diagnostic system and training a NN model when real flight data are not available. A combination of signature-based and $\mathrm{NN}$ model can enhance on-wing engine diagnostics.

Although simple and based on state-of-the-art knowledge, this framework was demonstrated to be suitable for engines fleet monitoring and diagnostics. Future work will focus on extending the capabilities of the framework to degradation monitoring and 
prognostics. The ultimate goal is to develop a decision support system for fleet condition-based maintenance and operations optimization.

\section{ACKNOWLEDGMENTS}

The authors gratefully acknowledge the Swedish Research Foundation, KKS, for the financial support.

\section{REFERENCES}

[1] L. Marinai, D. Probert, R. Singh, Prospects for aero gasturbine diagnostics: a review, Applied Energy 79 (2004) pp. 109-126.

[2] H.R. Depold, J. Siegel, Using diagnostics and prognostics to minimize the cost of ownership of gas turbines, Proceedings of ASME Turbo Expo 2006: Power for Land, Sea and Air, May 8-11, 2006, Barcelona, Spain, Paper number GT200691183.

[3] L.A. Urban, Gas path analysis applied to turbine engine condition monitoring, 1972, AIAA-72-1082.

[4] Y.G. Li, P. Nilkitsaranont, Gas turbine performance prognostic for condition-based maintenance, Applied $\begin{array}{llll}\text { Energy } & 86 & \text { (2009) } & \text { pp. }\end{array}$ doi:10.1016/j.apenergy.2009.02.011.

[5] C. Romessis, Ph. Kamboukos, K. Mathioudakis, The use of probabilistic reasoning to improve least squares based gas path diagnostics. Journal of Engineering for Gas Turbines and Power 129 (2007) 970-976.

[6] Volponi, A. J., Gas Turbine Parameter Corrections, ASME Journal of Engineering for Gas Turbines and Power, 121(4) (1999) 613-621.

[7] Y.G. Li, R. Singh, An advanced gas turbine gas path diagnostic system - PYTHIA, $17^{\text {th }}$ International Symposium on Air Breathing Engines, Munich, Germany, September 2005, Paper number ISABE-2005-1284.

[8] Mohammadreza Tahan, Elias Tsoutsanis, Masdi Muhammad, Z.A. Abdul Karim, Performance-based health monitoring, diagnostics and prognostics for condition-based maintenance of gas turbines: A review, Applied Energy 198 (2017) 122-144, doi:10.1016/j.apenergy.2017.04.048.

[9] GE Power, The digital transformation of electricity. 2016 https://www.ge.com/digital/sites/default/files/Power\%20Di gital $\% 20$ Solutions $\% 20$ Product $\% 20$ Catalog.pdf $\quad$ [accessed October 2017].

[10]GE Power Digital Solutions, GE Digital Twin: Analytic engine for the digital power plant. 2016.
https://www.ge.com/digital/sites/default/files/Digital-Twinfor-the-digital-power-plant-.pdf

[11] D. Gorinevsky, B. Matthews, R. Martin, Aircraft Anomaly Detection using Performance Models Trained on Fleet Data, 2012 Conference on Intelligent Data Understanding.

[12]A. N. Srivastava, Greener Aviation with Virtual Sensors: A Case Study, Data Mining and Knowledge Discovery, pp. 129, Oct. 2011.

[13]D. L. Iverson, Inductive system health monitoring, Proceedings of the 2004 International Conference on Artificial Intelligence (IC-AI04), Las Vegas, Nevada, June 2004.

[14] S. D. Bay, M. Schwabacher, Mining Distance-Based Outliers in Near Linear Time with Randomization and a Simple Pruning Rule, KDD '03: Proceedings of The Ninth ACM SIGKDD International Conference on Knowledge Discovery and Data Mining, New York, NY, 2003.

[15]L. Li, M. Gariel, R. Hansman, R. Palacios, Anomaly detection in onboard-recorded flight data using cluster analysis, Proceedings of $30^{\text {th }}$ IEEE/AIAA Digital Avionics Systems Conference (DASC), Oct. 2011, pp. 4A4-1 - 4A411.

[16]I. Roumeliotis, N. Aretakis, A. Alexiou, Industrial gas turbine health and performance assessment with field data, Journal of Engineering for Gas Turbines and Power 139 (2017) 051202

[17]E. Tsoutsanis, N. Meskin, M. Benammar, K. Khorasani, A component map tuning method for performance prediction and diagnostics of gas turbine compressors, Applied Energy 135 (2014) 572-85.

[18] N. Aretakis, I. Roumeliotis, A. Alexiou, C. Romesis and K. Mathioudakis, Turbofan Engine Health Assessment From Flight Data, Proceedings of ASME Turbo Expo 2014: Turbine Technical Conference and Exposition, doi:10.1115/GT2014-26443.

[19] M.J. Roemer, G.J. Kacprzynski, Advanced Diagnostic and Prognostic Technologies for Gas Turbine Engine Risk Assessment, Proceedings of ASME Turbo Expo 2000, May 8-11, 2000, Munich Germany, Paper number 2000-GT-30.

[20]N. Zhao, X. Wen, S. Li, A review on gas turbine anomaly detection for implementing health management, Proceedings of ASME Turbo Expo 2016: Turbomachinery Technical Conference and Exposition, June 13 - 17, 2016, Seoul, South Korea, Paper number GT2016-58135. 
[21]L. Marinai, R. Singh, A bias-tolerant gas path diagnostics approach based on fuzzy logic, $17^{\text {th }}$ International Symposium on Air Breathing Engines, 2005, Paper number ISABE-2005-1285.

[22]D.L. Simon, S. Borguet, O. Léonard, X. Zhang, Aircraft engine gas path diagnostic methods: Public benchmarking results, Proceedings of ASME Turbo Expo 2013: Turbomachinery Technical Conference and Exposition, June 3-7, 2013, San Antonio, Texas, USA, Paper number GT2013-95077

[23]H. zur Nieden, K. Fiedler, The influence of serial performance deviation of military jet engines on the diagnostic quality of the gas path analysis, $14^{\text {th }}$ International Symposium on Air Breathing Engines, Florence, Italy, Sept. 5-10, 1999, Paper number 99-7075.

[24]E. Chu, D. Gorinevsky, and S. Boyd, Scalable Statistical Monitoring of Fleet Data, Proceedings of the 18th World Congress, The International Federation of Automatic Control, Milano (Italy) August 28 - September 2, 2011.

[25]E. Chu, D. Gorinevsky, and S. Boyd, Detecting aircraft performance anomalies from cruise flight data, Proceedings of AIAA Infotech@Aerospace, Atlanta, GA, 2010.

[26] S. Borguet, O. Léonard, P. Dewallef, Regression-Based Modeling of a Fleet of Gas Turbine Engines for Performance Trending, Journal of Engineering for Gas Turbines and Power 2016, Vol. 138, pp. 021201-1, DOI: $10.1115 / 1.4031253$.

[27] H. Ohlsson, T. Chen, S. Khoshfetratpakazad, L. Ljung. S.S. Sastry, Scalable anomaly detection in large homogeneous populations, 2014, Automatica, Vol. 50 (5), pp. 1459-1465, doi:10.1016/j.automatica.2014.03.008

[28]D. Scheianu, Methods and results in remote monitoring and diagnosing a fleet of industrial gas turbines, Proceedings of ASME Turbo Expo 2014: Turbine Technical Conference and Exposition, June 16-20, 2014, Düsseldorf, Germany, Paper number GT2014-26068.
[29] A. Martinez, L. Sanchez, I. Couso, Improved life cycle cost - reduced engine maintenance through engine health monitoring genetic fuzzy system - Method validation and case study, Proceedings of ASME Turbo Expo 2014: Turbine Technical Conference and Exposition, June 16-20, 2014, Düsseldorf, Germany, Paper number GT2014-25639.

[30]M.L. Verbist, W.P.J. Visser, J.P. van Buijtenen, R. Duivis, Gas path analysis on KLM in-flight engine data, Proceedings of ASME Turbo Expo 2011: Turbine Technical Conference and Exposition, June 6-10, 2011, Vancouver, British Columbia, Canada, Paper number GT2011-45625.

[31]E Najafi Saatlou, KG Kyprianidis, V Sethi, AO Abu and P Pilidis, On the trade-off between minimum fuel burn and maximum time between overhaul for an intercooled aeroengine. Proceedings of the Institution of Mechanical Engineers, Part G: Journal of Aerospace Engineering 2014 228: 2424, DOI: $10.1177 / 0954410013518509$.

[32] G. Cerri, L. Chennaoui, A. Giovannelli, C. Salvini, Gas Path Analysis and Gas Turbine Re-mapping. Proceedings of ASME Turbo Expo 2011, June 6-10, 2011, Vancouver, British Columbia, Canada, GT2011-46424.

[33]KG Kyprianidis, RF Colmenares Quintero, DS Pascovici, SOT Ogaji, P Pilidis, AI Kalfas, EVA - a tool for environmental assessment of novel propulsion cycles. In: ASME TURBO EXPO 2008 proceedings, GT2008-50602, Berlin, Germany; 2008. http://dx.doi.org/10.1115/GT200850602.

[34] Walsh PP, Fletcher P. Gas turbine performance. 1st ed. Chichester, United Kingdom: Blackwell Science; 1998. ISBN 0-632-04874-3.

[35] Samuelsson S, Kyprianidis KG, Grönstedt T. Consistent Conceptual Design and Performance Modeling of Aero Engines. Proceedings of ASME Turbo Expo 2015: Turbomachinery Technical Conference and Exposition, June 15-19, 2015, Montreal, Canada, Paper number GT2015-43331. 